\title{
Post-translational modifications, subcellular relocation and release in apoptotic microparticles: apoptosis turns nuclear proteins into autoantigens
}

\author{
Jürgen Dieker and Sylviane Muller
}

Centre National de la Recherche Scientifique (CNRS), Institut de Biologie Moléculaire et Cellulaire, Strasbourg, France

\begin{abstract}
Autoantibodies against particular nuclear components, such as chromatin and snRNPs, are a characteristic feature of the autoimmune disease systemic lupus erythematosus. The last decade, evidence has suggested that apoptotic cells are the main source of autoantigens in this disease. Therefore, it has been proposed that protein modifications occurring during apoptosis lead to the formation of neo-epitopes, which can break the tolerance when apoptotic cells are not properly cleared. Indeed, many lupus autoantigens are prone to apoptosis-associated post-translational modifications and/or cleavage by caspases. In addition, lupus autoantigens are relocated from the nucleus to apoptotic blebs on the cell surface of early apoptotic cells. Therefore, to understand why certain nuclear proteins become autoantigens during apoptosis, it is important to know the apoptotic processing of these proteins. This review summarizes the current knowledge of apoptotic processing of lupus autoantigens and the possible effects on their encounter with the immune system in normal and autoimmune situations.
\end{abstract}

Keywords: systemic lupus erythematosus, autoantigens, post-translational modifications, apoptosis, apoptotic microparticles

\section{Introduction}

Many cells die each day in our body to establish tissue homeostasis, to remove unwanted immune cells, in development or during infections. Several tightly regulated pathways, called apoptosis, have evolved to ensure the disposal of dying cells and their debris as silent as possible without activating the immune system [1]. In contrast, necrosis is primarily considered as a non-silent pathway of cell death, which is supposed to activate the immune system. Apoptosis can be induced by different pathways, but finally all these pathways lead to the same result: the coordinated breakdown of cellular structures, of which the nucleus is the most striking [2]. Therefore, nuclear changes have been considered as the best applicable and most specific marker for apoptosis [3]. The nuclear changes include the condensation and fragmentation of chromatin and the clustering of many other nuclear components into so-called heterogeneous ectopic RNP-derived structures (HERDS) [4]. Another feature of apoptosis, and

Correspondence: S. Muller, CNRS UPR9021, Institut de Biologie Moléculaire et Cellulaire 15 Rue René Descartes, 67084 Strasbourg, France; tel.: (+333) 88417022,

fax.: (+333) 88610680, e-mail: S.Muller@ibmc.u-strasbg.fr not necrosis, is the appearance of many blebs on the cell surface, which contain cytoplasmic and nuclear components [5]. Both the nuclear changes and the appearance of surface blebs are early features of apoptosis, although their function is still unclear [2].

The autoimmune disease systemic lupus erythematosus (SLE) is characterized by autoantibodies directed mainly against nuclear structures [6,7]. The apoptotic cell has been proposed as the source of nuclear autoantigens targeted during lupus, since (i) nuclear autoantigens were identified in apoptotic surface blebs [8]; (ii) mice deficient in molecules involved in the removal of apoptotic cells develop lupus-like autoimmunity $[9,10]$; (iii) apoptotic cells, especially in combination with dendritic cells (DCs) are able to activate autoreactive T cells and induce an anti-nuclear immune response in mice [11-13]; and (iv) autoantibodies from lupus patients and mice preferably recognize modified proteins from apoptotic cells [14-20].

\section{Post-translational modifications of nuclear autoantigens}

Post-translational modifications of proteins, including acetylation, phosphorylation, methylation and citrullination, play an important role in the regulation of protein 
function by changing for instance the interaction with other proteins, the activity and/or the stability. Therefore, it is logical that apoptosis involves the modification of many proteins. Early during apoptosis nuclear processes, such as transcription and mRNA splicing, have to be deviated to transcribe genes encoding proapoptotic proteins [21], and finally these processes are fully terminated [2]. Post-translational modifications of histones have an essential function in the regulation of chromatin structure and gene transcription [22]. Indeed, changes in the post-translational modifications of histones have been identified in chromatin from apoptotic cells. Thus, histone H2B is phosphorylated on Ser14 during apoptosis [23], which has been associated with the condensation of chromatin [24]. In addition, changes in the acetylation of histones $\mathrm{H} 2 \mathrm{~A}, \mathrm{H} 3$ and $\mathrm{H} 4$ occur during apoptosis [19,25-28]. In different cell lines, using different apoptosis inducers, both apoptosis-associated acetylation and deacetylation of histones have been found. Interestingly, acetylated histone H4 is an important target of autoantibodies from lupus mice and patients [19]. In addition, injection of a $\mathrm{H} 4$ peptide acetylated on Lys8, 12 and 16 aggravated disease symptoms in lupus mice, whereas the non-acetylated H4 peptide showed no effect. A (pre-apoptotic) difference in the acetylation and methylation of histones was found in splenocytes form lupus mice compared to control mice [29]. Ubiquitinated H2A was identified as a target for lupus autoantibodies [30,31], however, so far only deubiquitination of histone $\mathrm{H} 2 \mathrm{~A}$ has been associated with apoptosis [32]. Dephosphorylation and poly(ADP)-ribosylation of histone $\mathrm{H} 1$ and phosphorylation of histone H2A, H2A.X and H3 have also associated with apoptosis [33-36]. Finally, transglutamination of histone H2B during apoptosis was found [37] and transglutamination was proposed to prevent the leakage of proteins from apoptotic cells [38]. Many other possible histone modifications have not been studied in association with apoptosis, whereas most modified histones have not been tested with autoantibodies from lupus mice and patients. In addition, modifications of DNA, such oxidation or methylation, can occur and might change the immunogenicity of DNA.

Modifications of RNA-associated proteins (RNPs) have been associated with the regulation of mRNA transcription and splicing [39]. Particularly, changes in the phosphorylation have been associated with apoptosis. SR proteins, which are important regulators of mRNA splicing, are dephosphorylated during Fas-induced apoptosis by protein phosphatase 1 [40]. Dephosphorylated SR proteins are specifically recognized by lupus autoantibodies [41]. Phosphorylated RNA polymerase II was one of the first identified modified targets of lupus autoantibodies $[42,43]$, however, changes in the phosphorylation state of RNA polymerase II, which determine its activity, have not been associated with apoptosis so far [44]. In addition, changes in the methylation level of Sm snRNPs have not been identified yet during apoptosis, while symmetrically-dimethylated arginine residues in the C-terminal tails of SmD1, D3 and BB' proteins are recognized by lupus autoantibodies [45]. Probably, the most striking modified lupus autoantigens associated with apoptosis is the spliceosomal U1-70K snRNP. The U1-70K protein is one of the U1 snRNP-specific proteins of the U1 snRNP particle and plays an important role in the recognition of $5^{\prime}$ splice sites on mRNA. Several reports have described that the apoptotic $40-\mathrm{kDa}$ fragment of the U1-70K protein generated after caspase cleavage is much better recognized in denatured conditions by autoantibodies from lupus mice and patients [16-18]. We have recently described that during apoptosis a specific change in the phosphorylation status of the U1-70K protein occurs (Fig. 1) [20]. First, the phosphorylation of Ser140 in the RNA recognition motif (RRM) increases directly after the induction of apoptosis. Then, simultaneously with the cleavage by caspase- 3 , a caspase-dependent dephosphorylation by protein phosphatase 1 of other residues in the U1-70K protein takes place. Interestingly, a peptide comprised of a sequence of the RNA binding domain including the phosphorylated Ser140, is recognized by autoreactive T cells [46].

In addition to post-translational modification, cleavage by proteases, such as caspases and granzymes, of many nuclear proteins occurs. Cleavage can affect the recognition of the affected protein by lupus autoantibodies [47].

\section{Relocation of nuclear proteins}

Morphological changes of the nucleus are considered to be a specific feature of apoptosis. Condensation and fragmentation of chromatin is a well-studied process [48]; however, many parts of this mechanism remain elusive. Caspases activate DNA cleaving enzymes such as caspase activated DNase (CAD) [49]. In addition, proteins such as the apoptosis-inducing factor (AIF) are translocated from mitochondria to the nucleus [50]. Both $\mathrm{CAD}$ and AIF are essential for the condensation of chromatin, although for different stages. In addition, the condensation of chromatin is associated with several modifications of histones (as described above). Some changes in the structure of chromatin might also result in the exposure of neo-epitopes. During the condensation and under the control of several DNases, chromatin starts to fragment [49]. This fragmentation results finallyin the release of small chromatin particles during late apoptosis (also called secondary necrosis). These chromatin particles are able to stimulate the immune system if they are bound to anti-chromatin autoantibodies [51]. Released chromatin particles have been found to contain HMGB1, a classical example of a damage-associated molecular pattern (DAMP) or alarmin [52]. HMGB1-containing 
chromatin can stimulate the immune system and has been identified in the circulation of lupus patients $[52,53]$.

While the chromatin condenses, other nuclear structures relocate into HERDS, which were described for the first time in a paper by Biggiogera et al. [54, reviewed in refs 4 and 55]. Early during apoptosis structures normally present in the interchromatin space, such as the interchromatin granules (also called nuclear speckles), perichromatin fibrils (sites of transcription) and perichromatin granules cluster together in HERDS. This clustering continues with the addition of domains of the nucleolus, which probably makes this process irreversible [4]. HERDS are based on structures, such as the interchromatin granules, which are resistant to proteases and nucleases. Therefore, proteins inside HERDS could be protected from degrading enzymes. HERDS contain many RNA-associated autoantigens, such as the U1-70K protein (Fig. 1 and ref [20]) and the Sm antigen [54], which are not degraded since they are still detectable by antibody probes. In addition, HERDS contain still detectable RNA [56]. Recently, it was found that proteins from the same nuclear structure show a different dynamical relocation during early apoptosis and cluster in different parts in the apoptotic cell [57]. The morphology of HERDS shown by electron microscopy shows the possible existence of specific domains inside HERDS (unpublished personal observations). However, data on the contents and mechanism leading to the formation of HERDS are scarce. One can imagine that HERDS have a different composition in different types of cells or under different conditions. In addition, the composition of HERDS might be different between normal and lupus situations.

\section{Release into apoptotic microparticles and encounter with the immune system}

After the formation of HERDS and the condensation of chromatin, these structures are partially or completely relocated to blebs on the cell surface. This relocation is dependent on the kinase ROCKI, which phosphorylates myosin and regulates the formation of surface blebs [58]. Transglutaminase activity has been found on sites of the cell membrane where apoptotic blebs are formed [59]. Transglutaminase is an enzyme that cross-links proteins and might therefore be involved in the clustering of proteins in structures like HERDS. Moreover, transglutaminase 2-deficient cells show a leakage of intracellular proteins [38]. The formation of apoptotic blebs seems to be a universal feature of apoptosis for many cells, although a different blebbing between adherent cells and cells growing in suspension has been described [60]. In addition, the formation of different kinds of blebs for one single cell has been found [8]. Thus, it was shown that two populations of surface blebs exist on keratinocytes, where proteins from the endoplasmic reticulum, ribo- somes and the RNP Ro52 relocate to the small blebs while chromatin, Ro60, La and snRNPs relocate to the larger blebs [8]. Autoantigens are exposed on the outside of apoptotic blebs and can be bound by autoantibodies $[61,62]$. Early during apoptosis, apoptotic blebs release from the apoptotic cell as apoptotic microparticles leaving the apoptotic cell body [63]. However, a detailed characterization of apoptotic blebs/microparticles for their contents and their stability is lacking so far. Importantly, most studies describe apoptotic cells that are obtained by low-speed centrifugation of cell cultures. When this method is applied apoptotic microparticles are lost, and their effect is therefore not taken into account.

The recognition of apoptotic cells by the immune system has been described extensively [64]. Generally, it is considered that apoptotic cells do not induce a proinflammatory response or even induce tolerance [1] and necrosis results in activation of the immune system. However, the story is not black and white, since apoptotic cells can propagate an immune response [65]. The activation of the immune system depends partly on the release of a recently identified class of molecules, the alarmins $[1,66]$. These molecules which have their 'normal' function inside the cell, can also act as a cytokine when released from the cell. In general, apoptotic cells have several mechanisms to keep alarmins inside the cell and prevent the activation of the immune system. These mechanisms are still mostly unexplored, but studies on the classic alarmin HMGB1 have revealed some important information. HMGB1 is a protein involved in bending of dsDNA, but can be released from necrotic cells and activate immune cells by binding to receptor of advanced glycosylation products (RAGE) or Toll-like receptor (TLR)-4 [65]. In apoptotic cells HMGB1 is kept inside by binding to hypoacetylated chromatin [67]. However, apoptotic cells do release (some) HMGB1 $[68,69]$, which is rendered inactive by reactive oxygen species originating from mitochrondria [69]. Very late apoptotic cells release chromatin particles, which contain HMGB1 that can activate immune cells [70]. Interestingly, chromatin isolated from the circulation of SLE patients is bound to HMGB1. In addition, HERDS might contain danger signals able to activate the immune system. Recently, a new potential alarmin present in a RNAassociated complex, i.e. SAP130 which is associated with the U2 snRNP particle, was identified [71]. This molecule could bind and activate marophages via the socalled Mincle receptor, a new member of the C-type lectin family. In addition, the RNA component of the U1 snRNP particle is able to activate TLR-7 [72,73]. In conclusion, chromatin and HERDS bound to danger molecules might increase the potency of apoptotic microparticles to induce an autoimmune response. Indeed, the activation of DCs by apoptotic bodies has been documented [74]. However, the mechanism leading to activation is not clear. 

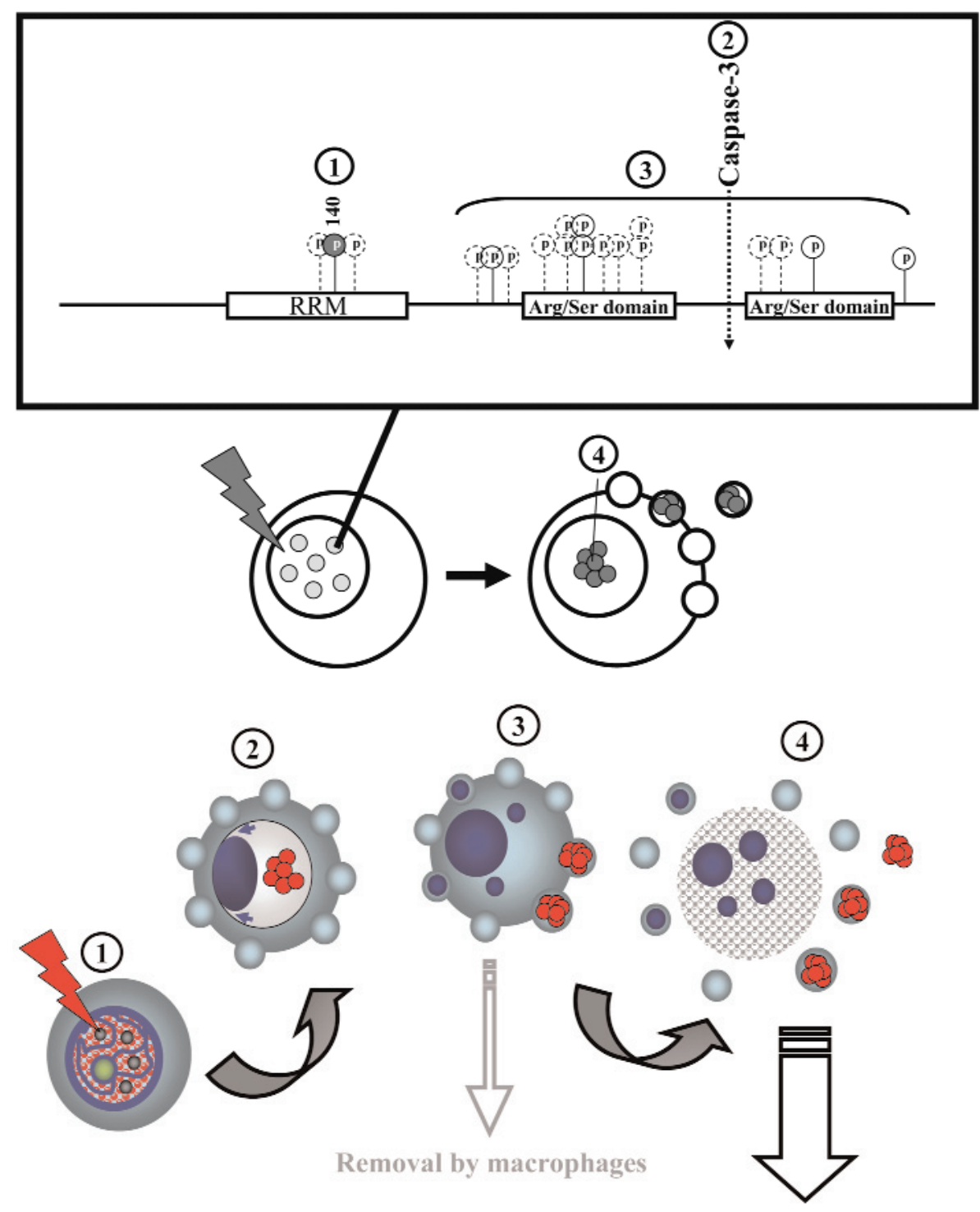

Activation of dendritic cells
Fig. 1. Overview of the apoptosis-associated modifications of the U1-70K protein as described in ref 20. Phosphorylation of Ser140 increases (1), followed by a simultaneous cleavage of the protein by caspase-3 (2) and dephosphorylation of other residues by protein phosphatase 1 (3). The modified protein is clustered in HERDS (4) and released in apoptotic microparticles.

Fig. 2. Model for the role of apoptosisassociated modifications in the development of lupus autoimmunity. (1) Posttranslational modifications of many nuclear proteins occur early during apoptosis, which might expose neo-epitopes. (2) Modified proteins and nucleic acids are relocated to condensed chromatin or HERDS. (3) Chromatin and HERDS are relocated to blebs on the surface of apoptotic cells. (4) Apoptotic blebs are released as microparticles when apoptotic cells are not properly removed and can activate the immune system.

\section{Summary}

Apoptotic cells should not induce an immune response under normal circumstances; however, this seems exactly what happens during the autoimmune disease SLE. Why apoptotic cells or proteins derived from apoptotic cells are able to induce an immune response during SLE remains largely unexplained. As summarized in this review, an increasing amount of evidence points to the apoptotic processing of proteins, particular of nuclear origin, as an important event (Fig. 2). Post-translational modifications of nuclear proteins might lead to the exposure of neo-epitopes. Subsequently, modified nuclear proteins are reorganized together with danger molecules (such as alarmins) into condensed clusters, which may protect them from nucleases and proteases. Apoptotic clusters are relocated to apoptotic blebs, which can be released as microparticles when apoptotic cells are not removed in time. Antigen-presenting cells are able to process these structures in a pro-inflammatory context and activate the immune system to produce autoantibodies against apoptotically-processed nuclear proteins. Future research has to fill in many of the gaps in this proposed mechanism and may lead to the development of new therapeutical approaches by preventing the activation of the immune system by modified apoptotic structures.

Acknowledgements: This work was supported by the Centre National de la Recherche Scientifique (CNRS) and a grant from the Fondation pour la Recherche Médicale (FRM) to JD.

\section{References}

[ 1] Kono H, Rock KL. How dying cells alert the immune system to danger. Nat Rev Immunol. 2008;8:279-89.

[ 2] Taylor RC, Cullen SP, Martin SJ. Apoptosis: controlled demolition at the cellular level. Nat Rev Mol Cell Biol. 2008;9: 231-41. 
[ 3] Kroemer G, Galluzzi L, Vandenabeele P, Abrams J, Alnemri ES, Baehrecke EH, Blagosklonny MV, El-Deiry WS, Golstein P, Green DR, Hengartner M, Knight RA, Kumar S, Lipton SA, Malorni W, Nunez G, Peter ME, Tschopp J, Yuan J, Piacentini M, Zhivotovsky B, Melino G. Nomenclature Committee on Cell Death 2009. Classification of cell death: recommendations of the Nomenclature Committee on Cell Death 2009. Cell Death Differ. 2009;16:3-11.

[4] Biggiogera M, Bottone MG, Scovassi AI, Soldani C, Vecchio L, Pellicciari C. Rearrangement of nuclear ribonucleoprotein (RNP)-containing structures during apoptosis and transcriptional arrest. Biol Cell. 2004;96:603-15.

[ 5] Charras GT. A short history of blebbing. J Microsc. 2008;231: 466-78.

[ 6] Dieker JW, van der Vlag J, Berden JH. Triggers for anti-chromatin autoantibody production in SLE. Lupus. 2002;11:856-64.

[ 7] Sherer Y, Gorstein A, Fritzler MJ, Shoenfeld Y. Autoantibody explosion in systemic lupus erythematosus: more than 100 different antibodies found in SLE patients. Semin Arthritis Rheum. 2004;34:501-37.

[ 8] Casciola-Rosen LA, Anhalt G, Rosen A. Autoantigens targeted in systemic lupus erythematosus are clustered in two populations of surface structures on apoptotic keratinocytes. J Exp Med. 1994;179:1317-30.

[ 9] Munoz LE, Gaipl US, Franz S, Sheriff A, Voll RE, Kalden JR, Herrmann M. SLE - a disease of clearance deficiency? Rheumatology. 2005;44:1101-7.

[10] Dieker JW, van der Vlag J, Berden JH. Deranged removal of apoptotic cells: its role in the genesis of lupus. Nephrol Dial Transplant. 2004;19:282-5.

[11] Tzeng TC, Suen JL, Chiang BL. Dendritic cells pulsed with apoptotic cells activate self-reactive T-cells of lupus mice both in vitro and in vivo. Rheumatology. 2006;45:1230-7.

[12] Bondanza A, Zimmermann VS, Dell'Antonio G, Cin ED, Balestrieri G, Tincani A, Amoura Z, Piette JC, Sabbadini MG, Rovere-Querini P, Manfredi AA. Requirement of dying cells and environmental adjuvants for the induction of autoimmunity. Arthritis Rheum. 2004;50:1549-60.

[13] Mevorach D, Zhou JL, Song X, Elkon KB. Systemic exposure to irradiated apoptotic cells induces autoantibody production. J Exp Med. 1998;188:387-92.

[14] Utz PJ, Hottelet M, Schur PH, Anderson P. Proteins phosphorylated during stress-induced apoptosis are common targets for autoantibody production in patients with systemic lupus erythematosus. J Exp Med. 1997; 185:843-54.

[15] Utz PJ, Anderson P. Posttranslational protein modifications, apoptosis, and the bypass of tolerance to autoantigens. Arthritis Rheum. 1998;41:1152-60.

[16] Greidinger EL, Foecking MF, Ranatunga S, Hoffman RW. Apoptotic U1-70 kd is antigenically distinct from the intact form of the U1-70-kd molecule. Arthritis Rheum. 2002;46: 1264-9.

[17] Greidinger EL, Foecking MF, Magee J, Wilson L, Ranatunga S, Ortmann RA, Hoffman RW. A major B cell epitope present on the apoptotic but not the intact form of the U1$70-\mathrm{kDa}$ ribonucleoprotein autoantigen. $J$ Immunol. 2004;172:709-16.

[18] Hof D, Raats JM, Pruijn GJ. Apoptotic modifications affect the autoreactivity of the U1 snRNP autoantigen. Autoimmun Rev. 2005;4:380-8.

[19] Dieker JW, Fransen JH, van Bavel CC, Briand JP, Jacobs CW, Muller S, Berden JH, van der Vlag J. Apoptosis-induced acetylation of histones is pathogenic in systemic lupus erythematosus. Arthritis Rheum. 2007;56:1921-33.

[20] Dieker J, Cisterna B, Monneaux F, Decossas M, van der Vlag J, Biggiogera M, Muller S. Apoptosis-linked changes in the phosphorylation status and subcellular localization of the spliceosomal autoantigen U1-70K. Cell Death Differ. 2008; 15:793-804.
[21] Schwerk C, Schulze-Osthoff K. Regulation of apoptosis by alternative pre-mRNA splicing. Mol Cell. 2005;19:1-13.

[22] Jenuwein T, Allis CD. Translating the histone code. Science. 2001;293:1074-80.

[23] Cheung WL, Ajiro K, Samejima K, Kloc M, Cheung P, Mizzen CA, Beeser A, Etkin LD, Chernoff J, Earnshaw WC, Allis CD. Apoptotic phosphorylation of histone H2B is mediated by mammalian sterile twenty kinase. Cell. 2003;113:507-17.

[24] Hu Y, Liu Z, Yang SJ, Ye K. Acinus-provoked protein kinase $C$ delta isoform activation is essential for apoptotic chromatin condensation. Cell Death Differ. 2007;14:2035-46.

[25] Boix-Chornet M, Fraga MF, Villar-Garea A, Caballero R, Espada J, Nunez A, Casado J, Largo C, Casal JI, Cigudosa JC, Franco L, Esteller M, Ballestar E. Release of hypoacetylated and trimethylated histone $\mathrm{H} 4$ is an epigenetic marker of early apoptosis. J Biol Chem. 2006;281:13540-7.

[26] Allera C, Lazzarini G, Patrone E, Alberti I, Barboro P, Sanna $\mathrm{P}$, Melchiori A, Parodi S, Balbi C. The condensation of chromatin in apoptotic thymocytes shows a specific structural change. J Biol Chem. 1997;272:10817-22.

[27] Wang D, Lippard SJ. Cisplatin-induced post-translational modification of histones H3 and H4. J Biol Chem. 2004;279: 20622-5.

[28] Rouaux C, Jokic N, Mbebi C, Boutillier S, Loeffler JP, Boutillier AL. Critical loss of CBP/p300 histone acetylase activity by caspase-6 during neurodegeneration. EMBO J. 2003;22: 6537-49.

[29] Garcia BA, Busby SA, Shabanowitz J, Hunt DF, Mishra N. Resetting the epigenetic histone code in the MRL-lpr/lpr mouse model of lupus by histone deacetylase inhibition. $J$ Proteome Res. 2005;4:2032-42.

[30] Plaué S, Muller S, van Regenmortel MH. A branched, synthetic octapeptide of ubiquitinated histone H2A as target of autoantibodies. $J$ Exp Med. 1989;169:1607-17.

[31] Elouaai F, Lulé J, Benoist H, Appolinaire-Pilipenko S, Atanassov C, Muller S, Fournié GJ. Autoimmunity to histones, ubiquitin, and ubiquitinated histone H2A in NZB $x$ NZW and MRL-lpr/lpr mice. Anti-histone antibodies are concentrated in glomerular eluates of lupus mice. Nephrol Dial Transplant. 1994;9:362-6.

[32] Mimnaugh EG, Kayastha G, McGovern NB, Hwang SG, Marcu MG, Trepel J, Cai SY, Marchesi VT, Neckers L. Caspase-dependent deubiquitination of monoubiquitinated nucleosomal histone $\mathrm{H} 2 \mathrm{~A}$ induced by diverse apoptogenic stimuli. Cell Death Differ. 2001;8:1182-96.

[33] Talasz H, Helliger W, Sarg B, Debbage PL, Puschendorf B, Lindner H. Hyperphosphorylation of histone H2A.X and dephosphorylation of histone H1 subtypes in the course of apoptosis. Cell Death Differ. 2002;9:27-39.

[34] Waring P, Khan T, Sjaarda A. Apoptosis induced by gliotoxin is preceded by phosphorylation of histone $\mathrm{H} 3$ and enhanced sensitivity of chromatin to nuclease digestion. $J$ Biol Chem. 1997;272:17929-36.

[35] Ajiro K. Histone H2B phosphorylation in mammalian apoptotic cells. An association with DNA fragmentation. $J$ Biol Chem. 2000;275:439-43.

[36] Yoon YS, Kim JW, Kang KW, Kim YS, Choi KH, Joe CO. Poly(ADP-ribosyl)ation of histone $\mathrm{H} 1$ correlates with internucleosomal DNA fragmentation during apoptosis. $J$ Biol Chem. 1996;271:9129-34.

[37] Piredda L, Farrace MG, Lo Bello M, Malorni W, Melino G, Petruzzelli R, Piacentini M. Identification of 'tissue' transglutaminase binding proteins in neural cells committed to apoptosis. FASEB J. 1999;13:355-64.

[38] Piredda L, Amendola A, Colizzi V, Davies PJ, Farrace MG, Fraziano M, Gentile V, Uray I, Piacentini M, Fesus L. Lack of 'tissue' transglutaminase protein cross-linking leads to leakage of macromolecules from dying cells: relationship to 
development of autoimmunity in MRLIpr/Ipr mice. Cell Death Differ. 1997;4:463-72.

[39] Stamm S. Regulation of alternative splicing by reversible protein phosphorylation. J Biol Chem. 2008;283:1223-7.

[40] Chalfant CE, Ogretmen B, Galadari S, Kroesen BJ, Pettus BJ, Hannun YA. FAS activation induces dephosphorylation of SR proteins; dependence on the de novo generation of ceramide and activation of protein phosphatase 1. J Biol Chem. 2001;276:44848-55.

[41] Neugebauer KM, Merrill JT, Wener MH, Lahita RG, Roth MB. SR proteins are autoantigens in patients with systemic lupus erythematosus. Importance of phosphoepitopes. Arthritis Rheum. 2000;43:1768-78.

[42] Satoh M, Ajmani AK, Ogasawara T, Langdon JJ, Hirakata M, Wang J, Reeves WH. Autoantibodies to RNA polymerase II are common in systemic lupus erythematosus and overlap syndrome. Specific recognition of the phosphorylated (IIO) form by a subset of human sera. J Clin Invest. 1994;94:1981-9.

[43] Stetler DA, Jacob ST. Phosphorylation of RNA polymerase I augments its interaction with autoantibodies of systemic lupus erythematosus patients. J Biol Chem. Yamasaki S, Ishikawa E, Sakuma M, Hara H, Ogata K, Saito T.

[44] Egloff S, Murphy S. Cracking the RNA polymerase II CTD code. Trends Genet. 2008;24:280-8.

[45] Brahms H, Raymackers J, Union A, de Keyser F, Meheus L, Lührmann $\mathrm{R}$. The C-terminal RG dipeptide repeats of the spliceosomal Sm proteins D1 and D3 contain symmetrical dimethylarginines, which form a major B-cell epitope for anti-Sm autoantibodies. $J$ Biol Chem. 2000;275:17122-9.

[46] Monneaux F, Lozano JM, Patarroyo ME, Briand JP, Muller S. $\mathrm{T}$ cell recognition and therapeutic effect of a phosphorylated synthetic peptide of the $70 \mathrm{~K}$ snRNP protein administered in MR/lpr mice. Eur J Immunol. 2003;33:287-96.

[47] Rosen A, Casciola-Rosen L. Autoantigens as substrates for apoptotic proteases: implications for the pathogenesis of systemic autoimmune disease. Cell Death Differ. 1999;6:6-12.

[48] Samejima K, Earnshaw WC. Trashing the genome: the role of nucleases during apoptosis. Nat Rev Mol Cell Biol. 2005;6:677-88.

[49] Enari M, Sakahira H, Yokoyama H, Okawa K, Iwamatsu A, Nagata S. A caspase-activated DNase that degrades DNA during apoptosis, and its inhibitor ICAD. Nature. 1998;391:43-50.

[50] Susin SA, Daugas E, Ravagnan L, Samejima K, Zamzami N, Loeffler M, Costantini P, Ferri KF, Irinopoulou T, Prévost MC, Brothers G, Mak TW, Penninger J, Earnshaw WC, Kroemer G. Two distinct pathways leading to nuclear apoptosis. $J$ Exp Med. 2000;192:571-80.

[51] Boulé MW, Broughton C, Mackay F, Akira S, Marshak-Rothstein A, Rifkin IR. Toll-like receptor 9-dependent and -independent dendritic cell activation by chromatin-immunoglobulin G complexes. J Exp Med. 2004;199:1631-40.

[52] Tian J, Avalos AM, Mao SY, Chen B, Senthil K, Wu H, Parroche P, Drabic S, Golenbock D, Sirois C, Hua J, An LL, Audoly L, La Rosa G, Bierhaus A, Naworth P, Marshak-Rothstein A, Crow MK, Fitzgerald KA, Latz E, Kiener PA, Coyle AJ. Toll-like receptor 9-dependent activation by DNA-containing immune complexes is mediated by HMGB1 and RAGE. Nat Immunol. 2007;8:487-96.

[53] Urbonaviciute V, Fürnrohr BG, Meister S, Munoz L, Heyder P, De Marchis F, Bianchi ME, Kirschning C, Wagner H, Manfredi AA, Kalden JR, Schett G, Rovere-Querini P, Herrmann $\mathrm{M}$, Voll RE. Induction of inflammatory and immune responses by HMGB1-nucleosome complexes: implications for the pathogenesis of SLE. J Exp Med. 2008;205:3007-18.

[54] Biggiogera M, Bottone MG, Martin TE, Uchiumi T, Pellicciari. Still immunodetectable nuclear RNPs are extruded from the cytoplasm of spontaneously apoptotic thymocytes. Exp Cell Res. 1997;234:512-20.
[55] Biggiogera M, Pellicciari C. Heterogeneous ectopic RNPderived structures (HERDS) are markers of transcriptional arrest. FASEB J. 2000;14:828-34.

[56] Biggiogera M, Bottone MG, Pellicciari C. Nuclear RNA is extruded from apoptotic cells. J Histochem Cytochem. 1998;46:999-1005.

[57] Scovassi AI, Bottone MG, Biggiogera M, Pellicciari C. Dynamic relocation of nuclear proteins during the execution phase of apoptosis. Biochem Pharmacol. 2008;76:1440-50.

[58] Coleman ML, Sahai EA, Yeo M, Bosch M, Dewar A, Olson MF. Membrane blebbing during apoptosis results from caspase-mediated activation of ROCK I. Nat Cell Biol. 2001;3:339-45.

[59] Maruyama W, Irie S, Sato TA. Morphological changes in the nucleus and actin cytoskeleton in the process of Fas-induced apoptosis in Jurkat T cells. Histochem J. 2000;32:495-503.

[60] Lane JD, Allan VJ, Woodman PG. Active relocation of chromatin and endoplasmic reticulum into blebs in late apoptotic cells. J Cell Sci. 2005;118:4059-71.

[61] Cocca BA, Cline AM, Radic MZ. Blebs and apoptotic bodies are B cell autoantigens. J Immunol. 2002;169:159-66.

[62] Radic M, Marion T, Monestier M. Nucleosomes are exposed at the cell surface in apoptosis. J Immunol. 2004;172:6692-700.

[63] Schiller M, Bekeredjian-Ding I, Heyder P, Blank N, Ho AD, Lorenz HM. Autoantigens are translocated into small apoptotic bodies during early stages of apoptosis. Cell Death Differ. 2008;15:183-91

[64] Ravichandran KS, Lorenz U. Engulfment of apoptotic cells: signals for a good meal. Nat Rev Immunol. 2007;7:964-74.

[65] Tesniere A, Apetoh L, Ghiringhelli F, Joza N, Panaretakis T, Kepp O, Schlemmer F, Zitvogel L, Kroemer G. Immunogenic cancer cell death: a key-lock paradigm. Curr Opin Immunol. 2008;20:504-11.

[66] Bianchi ME. DAMPs, PAMPs and alarmins: all we need to know about danger. J Leukoc Biol. 2007;81:1-5.

[67] Scaffidi P, Misteli T, Bianchi ME. Release of chromatin protein HMGB1 by necrotic cells triggers inflammation. Nature. 2002;418:191-5.

[68] Bell CW, Jiang W, Reich CF 3rd, Pisetsky DS. The extracellular release of HMGB1 during apoptotic cell death. Am J Physiol Cell Physiol. 2006;291:C1318-25.

[69] Kazama H, Ricci JE, Herndon JM, Hoppe G, Green DR, Ferguson TA. Induction of immunological tolerance by apoptotic cells requires caspase-dependent oxidation of high-mobility group box-1 protein. Immunity. 2008;29:21-32.

[70] Urbonaviciute V, Fürnrohr BG, Meister S, Munoz L, Heyder P, De Marchis F, Bianchi ME, Kirschning C, Wagner H, Manfredi AA, Kalden JR, Schett G, Rovere-Querini P, Herrmann $\mathrm{M}$, Voll RE. Induction of inflammatory and immune responses by HMGB1-nucleosome complexes: implications for the pathogenesis of SLE. $J$ Exp Med. 2008;205:3007-18.

[71] Mincle is an ITAM-coupled activating receptor that senses damaged cells. Nat Immunol. 2008;9:1179-88.

[72] Kelly-Scumpia KM, Nacionales DC, Scumpia PO, Weinstein JS, Narain S, Moldawer LL, Satoh M, Reeves WH. In vivo adjuvant activity of the RNA component of the Sm/RNP lupus autoantigen. Arthritis Rheum. 2007;56:3379-86.

[73] Hoffman RW, Gazitt T, Foecking MF, Ortmann RA, Misfeldt M, Jorgenson R, Young SL, Greidinger EL. U1 RNA induces innate immunity signaling. Arthritis Rheum. 2004;50:2891-6.

[74] Heyder P, Bekeredjian-Ding I, Parcina M, Blank N, Ho AD, Herrmann M, Lorenz HM, Heeg K, Schiller M. Purified apoptotic bodies stimulate plasmacytoid dendritic cells to produce IFN-alpha. Autoimmunity. 2007;40:331-2.

Submitted: 3 January, 2009 Accepted after reviews: 4 February, 2009 